Review

\title{
Clinical importance of the anterior choroidal artery: a review of the literature
}

\author{
Jing $\mathrm{Yu}^{1^{*}}$, Ning $\mathrm{Xu}^{2^{*}}$, Ying Zhao ${ }^{3}$, and Jinlu $\mathrm{Yu}^{\mathbf{2}^{\bowtie}}$ \\ 1. Department of Surgery and Operating Room, The First Hospital of Jilin University, Changchun, 130021, China \\ 2. Department of Neurosurgery, The First Hospital of Jilin University, Changchun, 130021, China \\ 3. Department of Training, The First Hospital of Jilin University, Changchun, 130021, China \\ *These authors contributed equally to this work. \\ $\triangle$ Corresponding author: Jinlu Yu, Department of Neurosurgery, The First Hospital of Jilin University, 71 Xinmin Avenue, Changchun 130021, China. Email: \\ jlyu@jlu.edu.cn \\ (C) Ivyspring International Publisher. This is an open access article distributed under the terms of the Creative Commons Attribution (CC BY-NC) license \\ (https://creativecommons.org/licenses/by-nc/4.0/). See http://ivyspring.com/terms for full terms and conditions.
}

Received: 2017.09.01; Accepted: 2018.01.05; Published: 2018.02.12

\begin{abstract}
The anterior choroidal artery (AChA) is a critical artery in brain physiology and function. The AChA is involved in many diseases, including aneurysm, brain infarct, Moyamoya disease (MMD), brain tumor, arteriovenous malformation (AVM), etc. The AChA is vulnerable to damage during the treatment of these diseases and is thus a very important vessel. However, a comprehensive systematic review of the importance of the AChA is currently lacking. In this study, we used the PUBMED database to perform a literature review of the AChA to increase our understanding of its role in neurophysiology. Although the $\mathrm{AChA}$ is a small thin artery, it supplies an extremely important region of the brain. The AChA consists of cisternal and plexal segments, and the point of entry into the choroidal plexus is known as the plexal point. During treatment for aneurysms, tumors, AVM or AVF, the AChA cisternal segments should be preserved as a pathway to prevent the infarction of the AChA target region in the brain. In MMD, a dilated AChA provides collateral flow for posterior circulation. In brain infarcts, rapid treatment is necessary to prevent brain damage. In Parkinson disease (PD), the role of the AChA is unclear. In trauma, the AChA can tear and result in intracranial hematoma. In addition, both chronic and non-chronic branch vessel occlusions in the AChA are clinically silent and should not deter aneurysm treatment with flow diversion. Based on the data available, the AChA is a highly essential vessel.
\end{abstract}

Key words: Anterior choroidal artery; Clinical importance; Review

\section{Introduction}

The anterior choroidal artery (AChA) is a small, thin artery that commonly originates $2-5 \mathrm{~mm}$ distal to the posterior communicating artery [1,2]. Despite its small size, the AChA has perforating branches [3]. The AChA supplies an extremely important region of the brain that includes the posterior limb of the internal capsule, optical tract, lateral geniculate body, medial temporal lobe, and medial area of the pallidum [4]. The AChA consists of cisternal and plexal segments, and the point of entry into the choroidal plexus is known as the plexal point [5]. AChAs may be short and dysplastic or long and hyperplastic; therefore, the AChAs feeding the choroid plexus are classified as the long-course type, whereas all other AChAs are classified as the short-course type [6-9].

The long-course AChA has anastomoses with the lateral posterior choroidal artery, the posterior cerebral artery and the posterior communicating artery $[10,11]$. Even when the proximal AChA or internal carotid artery (ICA) are occluded, retrograde filling of the AChAs from the posterior circulation has been observed on a vertebral angiogram [12]. Even if the AChA exhibits this collateral circulation, the AChA is highly vulnerable, and infarcts within this vessel can result in a devastating outcome for patients [13].

The AChA is involved in many diseases, including aneurysm, brain infarct, Moyamoya disease (MMD), brain tumor, arteriovenous malformation 
(AVM), etc. During treatment, the AChA vulnerable to damage; therefore, the AChA is an important vessel. However, a comprehensive systematic review of the importance of the AChA is currently lacking. In this paper, we performed a comprehensive literature review to increase the understanding of the role of the AChA.

\section{Aneurysm}

Of all diseases that involve the AChA, aneurysms are the most common lesions that can originate from the ICA near the origin of the AChA or arise from the distal AChA [14]. Aneurysms at the junction of the AChA and ICA account for $2 \%-4 \%$ of all intracranial aneurysms; however, distal AChA aneurysms are rare as fewer than 40 cases have been reported to date [15, 16]. Most distal AChA aneurysms are located in the choroidal segment beyond the plexal point and are associated with MMD, whereas AChA aneurysms in the cisternal segment are extremely rare $[17,18]$.

\section{Pathogenesis}

There are various etiologies for AChA aneurysms. Aneurysms that originate from the ICA have the same etiology as other intracranial berry aneurysms. However, distal AChA aneurysms are often closely associated with MMD likely because of increased hemodynamic stress during its function as a collateral vessel rather than because of AVM, atherosclerosis, or hemodynamic alterations after arterial occlusion [16, 19, 20].

\section{Clinical manifestation}

Most unruptured AChA aneurysms have no clinical manifestation, but oculomotor nerve palsy can occur in AChA aneurysms near the oculomotor nerve [21]. However, most AChA aneurysms are undetected until they rupture. Ruptured aneurysms that either originate from the ICA or are located in the cisternal segment often present with subarachnoid hemorrhage. However, distal AChA aneurysms often present with isolated medial temporal intracerebral hematoma with intraventricular extension $[22,23]$.

\section{Treatment}

Among the appropriate treatments for AChA aneurysms, surgical clipping and resection or endovascular embolization remain the most ideal approaches [15, 24]. The treatments for aneurysms at the junction of the AChA and ICA are similar to those for other supraclinoid ICA aneurysms. Because the AChA is vulnerable, inadvertent damage to and occlusion of the AChA during clipping and embolization may have deleterious clinical consequences; therefore, treatments of aneurysms involving the AChA must be performed cautiously $[25,26]$. Compared with clipping, coiling AChA aneurysms had a significantly lower incidence of AChA infarction [27]. For instance, in a study performed by Bohnstedt et al. in 2013, the ischemic complication rate following surgical treatment of AChA aneurysms was $12 \%$, whereas coiling AChA aneurysms as an alternative to clipping was associated with a 5.5\% risk of ischemia [28].

Furthermore, treatments for distal AChA aneurysms are different from those for proximal AChA aneurysms. Treating aneurysms is difficult because of their lack of accessibility and small size [29]. In distal AChA aneurysms, the aneurysm location and the preservation of the parent artery are two major prognostic factors in both surgical clipping and endovascular therapy [30]. When distal AChA aneurysms are beyond the plexal point, the AChA can be sacrificed or preserved. In distal AChA aneurysms, if the treatment requires AChA occlusion, preoperative provocative testing should be considered [31]. Although surgery is considered the traditional treatment for distal AChA aneurysms, the potential use of endovascular techniques has recently gained increasing attention $[27,32,33]$.

In conclusion, AChA aneurysms can be divided into aneurysms from the ICA near either the origin of the AChA or the distal AChA. For both types of aneurysms, clipping and coiling are good treatment options; however, for distal AChA aneurysms, the treatments are different. If a distal AChA aneurysm is beyond the plexal point, the AChA can be sacrificed or preserved.

\section{Brain infarct}

The AChA has some anastomoses with the posterior choroidal artery and posterior cerebral artery branches. However, the perforating arteries toward the posterior limb of the internal capsule do not receive a collateral supply; thus, when the AChA is occluded, this territory will infarct. Additionally, the clinical spectrum of AChA infarcts is increasing [34]. These symptoms, including the triad of hemiparesis, hemianesthesia, and hemianopia, mainly manifest in AChA syndrome [35]. AChA syndrome may fluctuate from progression to complete regression; this is likely because the growing infarct or progressive tissue destruction involves corticospinal tract fibers [36]. A recent study in patients with AChA infarcts observed a loss of corticospinal tract fibers, and decreased fractional anisotropy may be an indicator of an unfavorable outcome [37].

The pathogenesis of AChA infarcts is heterogeneous, including small and large artery 
disease; thus, AChA infarcts can be divided into small vessel and large vessel infarcts [38]. Occlusive diseases of small penetrating arteries compose most AChA infarcts, including small vessel infarctions due to lupus and vasculitis [39]. However, in 1994, Leys et al. showed that most AChA territory infarcts are not due to small vessel occlusions, particularly in patients with involvement of both the subcortical and mesio-temporal territories of the AChA [40]. The involvement of the AChA territory in massive infarcts is primarily due to cardioembolic occlusion of the ICA $[41,42]$. Large AChA infarcts differ from small AChA infarcts in that large infarcts $(\geq 20 \mathrm{~mm})$ are more frequently associated with stroke evolution and worse clinical outcomes than smaller AChA ischemic lesions [43]. In addition, in patients with AChA infarcts, a perfusion deficit on MRI with a concomitant larger DWI lesion size is associated with worse clinical outcomes [44].

AChA infarcts, particularly large AChA infarcts, should be treated [45]. For instance, in 2014, Wu et al. studied 118 consecutive adult patients with acute large AChA infarcts and found that thrombolytic therapy was the only determinant of stroke evolution, reduced the risk of stroke evolution and improved functional outcome [46]. However, the outcome of thrombolytic therapy is controversial; for instance, Chausson et al. concluded in the same year that there was no convincing evidence of the positive effects of intravenous thrombolysis in AChA infarction [47].

In conclusion, the AChA is a vulnerable artery, and poor outcomes are expected following AChA infarcts. AChA infarcts can be divided into small vessel and large vessel infarcts, and thrombolytic therapy may be effective for large vessel infarcts.

\section{Moyamoya disease}

MMD is a chronic occlusive cerebrovascular disease characterized by bilateral stenosis or occlusion at the terminal portion of the ICA and the eponymous vessels at the base of the brain [48, 49]. The site of occlusion or stenosis in the terminal portion of the ICA can occur in one of the following four sites: site 1, the top of the ICA or the first segment of the anterior cerebral artery/the first segment of the middle cerebral artery; site 2, distal to the AChA; site 3, between the AChA and posterior communicating artery; and site 4, proximal to the posterior communicating artery [50]. If occlusion or stenosis occurs at sites 1 or 2 , the AChA can be preserved. Thus, the AChA may play a highly critical role in MMD.

\section{Dilation of the AChA}

In MMD, collaterals are more likely to arise from the choroidal arteries; therefore, the AChA may act as a major collateral route because it is frequently dilated and exhibits abnormal extension of many branches. The angiographic findings of the AChA can be considered grade 2 according to Suzuki's classification, and the AChA shows dilation and extension beyond the choroidal fissure [51]. The distal AChA can establish a dominant anastomosis with the posterior choroidal artery, and when it functions as a collateral vessel to increase blood flow, the hemodynamic load in the vessels supplying the walls of the posterior areas of the ventricles and the periventricular region is increased [52].

\section{Diseases from the AChA}

In MMD, an abnormally dilated AChA might be burdened with abnormal distension stress. Under such a hemodynamically stressed state, the dilated branches of the AChA may be more fragile, and the choroidal arteries and their anastomotic channels may rupture and produce parenchymal hematomas or intraventricular hemorrhage [53, 54]. Intracranial hemorrhages from dilated AChAs in MMD most commonly occur in adults and are rare in children. However, hemorrhage of a dilated AChA can even occur in children. For instance, in 1991, Kameyama et al. reported an 8-year-old girl who presented bilateral intraventricular hemorrhage from a dilated AChA [55]. In addition, an aneurysm could develop from an outpouching of the vessel wall in some fragile portions of the artery that function in maintaining prominent collateral circulation [56].

\section{Therapeutic strategy}

In MMD, a direct bypass may decrease the blood flow in the AChA and prevent recurrent bleeding, and even an indirect revascularization procedure alone may be an effective treatment. For instance, in 2016, Huang et al. reported an MMD patient who experienced intraventricular hemorrhage from weak spots in the distal AChA. An encephaloduroarteriosynangiosis was performed to decrease the hemodynamic overload on the AChA, and the follow-up procedure successfully induced the regression of all the weak points [53]. Furthermore, Kameyama et al. reported an 8-year-old girl with an intraventricular hemorrhage from the dilated AChA who received a ventriculoperitoneal shunt, and an encephalomyosynangiosis prevented recurrent bleeding for over 6 years [55].

Distal AChA aneurysms in MMD can be treated endovascularly with embolization [57]. However, disturbing the MMD collaterals should be avoided when using a liquid embolization material. For instance, in 2014, Murakami et al. reported a pregnant 
32-year-old MMD patient with a ruptured aneurysm of the distal AChA that was embolized using N-butyl cyanoacrylate. After surgery, the MR imaging showed ischemic changes in the ventral posterolateral nucleus of the thalamus without neurological deficits [58].

In conclusion, the AChA is a "double-edged sword" in MMD. On one hand, the dilated AChA acts as collateral vessels to prevent brain ischemia; on the other hand, due to the resulting hemodynamic stress, the branches of the AChA may rupture and even form an aneurysm in the AChA. Following intracranial bleeding, both direct and indirect revascularization may be effective for preventing recurrent bleeding.

\section{Brain tumors}

The AChA can provide a blood supply to many intracranial tumors, particularly those located in the lateral ventricle; some examples include meningiomas [59], choroid papilloma [60] and gliomas [61]. In cerebral angiograms, these tumors were shown to be vascular-rich and primarily fed by the AChA. Other feeders, such as the thalamoperforating or posterior choroidal arteries, are occasionally involved [62]. The hypervascular nature of the lesions in the lateral ventricle imposes challenges for surgical treatment; therefore, obliterating the feeders from the AChA before surgery could reduce hemorrhage and facilitate the surgery. In addition, occluding the feeding arteries can decrease the operative time, and preoperative embolization should be advocated [63].

The AChA feeds critical regions of the brain, and there is a relative lack of collaterals for these regions $[4,64]$. Thus, the migration of embolic agents through the AChA might cause serious neurological deficits. The AChA consists of cisternal and plexal segments, and the point of entry into the choroidal plexus is known as the plexal point [5]. Successful embolization requires the catheter to enter the plexal segment beyond the plexal point. During injection, care should be taken to prevent reverse flow of the embolic agent, which might lead to obliteration of normal vessels. In addition, when performing an embolization, a provocative test is needed, i.e., amobarbital can be injected after advancing the microcatheter beyond the plexal point [65]. If the test is negative, the embolization can be performed.

Many materials can be used. The best embolization results are achieved using small or liquid agents that can penetrate the tumor bed and embolize the vessels at the capillary level, but these agents are also the most dangerous because they can damage normal structures [66]. Thus, caution must be taken when these embolic agents migrate. Several agents can be used; for instance, in 1992, Oyama et al. used microfibrillar collagen to embolize a 53-year-old female with a large meningioma in the right trigone [59]. Recently, superselective injection using Onyx (EV3, Irvine, CA) as the embolic agent has been utilized [66]. Moreover, recent advances in microcatheter and microwire technologies currently make these once complex lesions more amenable to endovascular therapy.

In conclusion, for brain tumors primarily fed by the AChA, preoperative embolization should be attempted, but during the embolization, a microcatheter should be navigated beyond the plexal point and as close to the tumor site as possible; furthermore, during the injection, the speed should be extremely slow to avoid excessive reflux of the embolic agent.

\section{Arteriovenous malformations}

AVMs fed by the AChA are difficult to treat because surgical treatment can cause a high incidence of neurological deficits; however, in 1984, Fujita et al. reported four cases of AVM of the AChA that were successfully removed surgically [67]. An AVM supplied by the cisternal segment of the AChA and a shorter lesion-to-corticospinal tract distance were crucial risk factors favoring removal [68]. Currently, AVM embolization via the AChA may be an appropriate treatment option prior to surgery and radiation therapy or serve as a curative procedure. The goals of preoperative embolization are to eliminate the deep feeding arteries and to secure AVM-related aneurysms [69]. Good outcomes can be achieved with AVM embolization. For instance, in 2017, Lv et al. performed 4 AVM embolizations through the AChA; among these cases, 3 AVMs achieved curative embolization, and fourth case was a pre-surgical adjunctive procedure [70].

However, AVM embolization through the AChA is challenging and dangerous because the AChA supplies crucial brain structures, is of small caliber, and lacks collateral vessels [71]. Thus, during embolization through the AChA, the microcatheter tip should be advanced distally beyond the plexal point to avoid serious ischemic complications. However, even following this recommendation, the risks of ischemia are high. For instance, in 2017, Elkordy et al. performed 8 embolizations of ruptured AVMs through the AChA; among these cases, 2 patients suffered persistent hemiparesis [72]. Approximately $38 \%$ of capsulo-thalamic arteries arising from the AChA originate from the first part of the plexal segment, and this variation could be an important risk factor [73]. In contrast, embolization from the cisternal segment of the AChA does not always result in ischemic complications, suggesting a potential collateral circulation [74].

To minimize ischemic complications, some 
authors recommend superselective provocative testing with propofol using motor-evoked potential monitoring to manage AVMs fed by the AChA [75]. In addition to ischemic complications, certain catheterization-related technique complications should be considered. For instance, in 1991, Dowd et al. performed AVM embolization through the AChA in 15 patients; among these cases, 2 suffered hemorrhagic complications due to AChA perforation during the catheterization [76]. However, the incidence of catheterization-related complications has recently decreased due to the development of modern microcatheters, including smaller flow-directed catheters. Furthermore, AChAs that feed AVMs are usually dilated sufficiently to allow for deep catheterization with the currently available microcatheters.

In conclusion, embolization through the AChA may be an appropriate treatment option when the risk of surgery or radiosurgery is high. However, AVM embolization through the AChA is challenging, and ischemic complications can occur during the embolization of AVMs through the AChA. AVM embolization through the AChA should be performed with caution.

\section{Other diseases}

\section{Parkinson disease}

Parkinson disease (PD) is a neurodegenerative brain disorder that progresses slowly. This clinical syndrome is characterized by lesions in the basal ganglia (predominantly in the substantia nigra), and symptoms include tremor, bradykinesia, rigidity, and postural instability $[77,78]$. The AChA may play a role in PD because, in rare cases, $\mathrm{PD}$ may arise due to AChA territorial infarcts affecting the basal ganglial structures and the striatal pre-synaptic dopaminergic pathways [79]. Such a scenario is typical of vascular parkinsonism in its "pure definition", i.e., parkinsonism shortly following an acute territorial stroke [80].

By contrast, because the AChA supplies certain areas pathologically affected by $\mathrm{PD}$, occlusion of the AChA may alleviate parkinsonian symptoms. For instance, in 1953, Cooper et al. reported dramatic amelioration of parkinsonism after ligation of the AChA in 8 patients with severely advanced disease and concluded that the procedure had been invariably followed by the disappearance of most of the rigidity and cogwheelism; additionally, neither hemiplegia nor hemianesthesia occurred [81, 82]. However, the methods used were controversial [83]. In addition to $\mathrm{PD}, \mathrm{AChA}$ ischemic stroke may present as other movement disorders such as tonic spasm [84].

In conclusion, the AChA can play a role in the induction and alleviation of PD, but AChA occlusion for the treatment of $P D$ is uncertain and uncontrollable.

\section{Traumatic AChA rupture}

High-velocity impacts and acceleration/deceleration forces due to trauma generate shear stress in lenticulostriate arteries or AChAs, which leads to basal ganglia hemorrhage [85]. These hemorrhages may also be caused by traumatic pseudoaneurysms [86]. An injury to the AChA can result in pallidal hemorrhage or intracerebral hematomas in the posterior limb of the internal capsule and the upper part of the right cerebral peduncle [87]. In 1959, Mosberg et al. reviewed 20 autopsy cases with traumatic pallidal hemorrhage and postulated that the lesion-producing mechanism involved the intracerebral twigs of the AChA [88]. In addition, the mechanism by which the AChA tore might have impacted the parietal region directed toward the tentorium [87].

In rare cases, severe head trauma can resect the cisternal segment of the AChA, which reveals a diffuse traumatic subarachnoid hemorrhage (tSAH). The likely mechanism for the resected AChA is a sharp blow to the head causing a marked brain shift leading to stretching and eventual tearing of the AChA between the ICA and the neurovascular bundle [89]. A tSAH from the AChA is rare because most tSAHs are associated with the rupture of the basilar artery, vertebral artery, or ICA [90-92]. Treatment is difficult when the AChA ruptures. For instance, in 2014, Kim et al. described a patient with severe trauma due to a traffic accident who underwent endovascular coil packing to control the bleeding, but this approach failed, and the patient died 3 hours after sustaining the injuries [89].

In conclusion, the AChA can be injured during traffic accidents due to the intense acceleration/deceleration forces within the skull. More often, the injury can result in basal ganglia hemorrhage, and in rare cases, a tSAH can occur due to AChA resection.

\section{Pial arteriovenous fistula}

A cerebral pial arteriovenous fistula (PAVF) is a direct connection between the intracranial artery and vein without a nidus, and the vein often develops venous pouches of different sizes. Cerebral PAVF can occur during the early months of life in any location in the brain but are most commonly found in the supratentorial region [93]. Cerebral PAVF involving the AChA is extremely rare but not unheard of. For instance, in 2009, Rivera et al. reported a single-hole cerebral AVF between the AChA and the basal vein of 
Rosenthal in a 4-month-old male infant [94]. Cerebral PAVF should be considered congenital.

A high-flow PAVF is dangerous because intraparenchymal hemorrhage can occur. The spontaneous closure of high-flow PAVFs is infrequent; therefore, treatment is needed. Currently, endovascular management is the first-line treatment of choice for PAVFs, and the goal is to close feeders at the entry point to the vein [95]. Because the AChA is a vulnerable artery, treatment should be performed with caution. For endovascular treatment, coiling is a better choice than glue because the AChA is too short to prevent dangerous reflux during glue embolization.

In conclusion, the AChA can be involved in PAVF, although its involvement is rare. Currently, the AChA may be dilated, and coiling is a good treatment choice.

\section{Fate after flow-diverting stent deployment}

Flow-diverting stent (FDS) is a self-expanding apparatus with a high metal surface area coverage. After covering the neck of the aneurysm, an FDS induces aneurysm thrombosis and thereby cures the aneurysm [96]. Theoretically, FDS can cause occlusion of the perforating branches. In a large series, the long-term incidence of radiographic side branch arterial occlusion after coverage by FDS was $15.8 \%$ [97]. In another large series, the side branch occlusion incidence was 20\% [98]. However, terminal branch vessels such as the AChA can often remain patent and maintain blood flow [99]. For instance, in 2015, Neki et al. reported 20 consecutive patients who underwent procedures involving the unavoidable covering of the AChA using a single FDS during endovascular therapy, and in all the cases, the AChA remained patent without any flow changes [6].

However, the AChA can undoubtedly be occluded by an FDS. For instance, in a small study conducted by Brinjikji et al. in 2015, fifteen aneurysms were treated by placing an FDS across the AChA ostium, and 1 patient suffered chronic occlusion of the AChA [100]. Although the AChA may be occluded during follow-up, FDS placement had no immediate effect on the AChA blood flow, and none of the patients complained of transient or permanent symptoms related to an AChA occlusion. The AChA was rarely occluded, and no symptoms relating to AChA occlusion were observed because an FDS limits the aneurysmal blood flow but maintains the blood flow into large vessels and perforating vessels covered by the device [101].

In conclusion, because the AChA has anastomoses with the posterior circulation at the level of the choroid plexus, lateral geniculate body, or proximal portions of the posterior cerebral artery (regardless of whether the AChA is chronically occluded), branch vessel occlusions are clinically silent and should not deter aneurysm treatments involving flow diversion.

\section{Summary}

Although the AChA is a small thin artery, it supplies an extremely critical region of the brain. The AChA consists of cisternal and plexal segments, and the point of entry into the choroidal plexus is known as the plexal point. The AChA can be involved in many diseases, including aneurysm, brain infarct, MMD, brain tumor, AVM and traumatic cerebral hemorrhage. During treatment for aneurysms, tumors, AVM or AVF, the AChA cisternal segments should be preserved as a pathway to prevent the infarction of the critical regions of the brain that receive their blood supply from the AChA. In MMD, a dilated AChA provides important collateral circulation along with posterior circulation. In brain infarcts, rapid treatment is necessary to avoid critical brain damage. In PD, the AChA plays an uncertain role. In trauma, the AChA can tear, leading to an intracranial hematoma. In addition, regardless of whether the AChA is chronically occluded, branch vessel occlusions are clinically silent and should not deter aneurysm treatments involving flow diversion. Thus, the AChA is a very important vessel.

The outline and key important points regarding the AChA are summarized in table 1.

Table 1. Outline and key important points regarding the AChA

\begin{tabular}{|c|c|c|}
\hline Outline & Key point & $\begin{array}{l}\text { Recommended } \\
\text { documents }\end{array}$ \\
\hline Anatomy & $\begin{array}{l}\text { AChA is a small thin artery that supplies an extremely critical region of the brain. The AChA consists of cisternal and plexal } \\
\text { segments, and the point of entry into the choroidal plexus is known as the plexal point. The AChA has anastomoses with the } \\
\text { lateral posterior choroidal artery, the posterior cerebral artery and the posterior communicating artery. }\end{array}$ & {$[1,2,7]$} \\
\hline Aneurysm & $\begin{array}{l}\text { AChA aneurysms can be divided into aneurysms from the ICA near the origin of the AChA and in the distal AChA. Clipping and } \\
\text { coiling are good choices for both types of aneurysms. For distal AChA aneurysms, the treatments are different. When distal } \\
\text { AChA aneurysms are beyond the plexal point, the AChA can be sacrificed or preserved. }\end{array}$ & {$[14,17,27,28]$} \\
\hline Brain Infarct & $\begin{array}{l}\text { The AChA is a highly vulnerable artery. A poor outcome is common for AChA infarcts. AChA infarcts can be divided into small } \\
\text { vessel and large vessel infarcts. For large vessel infarcts, thrombolytic therapy may be effective. }\end{array}$ & {$[38,43,46,47]$} \\
\hline MMD & The AChA is a "double-edged sword" in MMD. On one hand, a dilated AChA acts as a collateral vessel to prevent brain ischemia; & {$[50,52,57]$} \\
\hline
\end{tabular}


on the other hand, due to hemodynamic stress, the branches of the AChA may rupture, and an aneurysm may even form in the AChA. Following intracranial bleeding, both direct and indirect revascularization may be effective in preventing recurrent bleeding.

Brain tumor For brain tumors fed primarily by the AChA, preoperative embolization should be attempted, but during embolization, the microcatheter should be navigated beyond the plexal point and as close to the tumor site as possible. During the injection, the speed should be extremely slow to avoid excessive reflux of the embolic agent.

AVMs AVM embolization through the AChA may be an appropriate treatment option when the risk of surgery or radiosurgery is high. [69, 72] However, AVM embolization through the AChA is challenging, and ischemic complications can occur during the embolization of AVMs through the AChA.

AChA: anterior choroidal artery; MMD: moyamoya disease; AVM: arteriovenous malformation

\section{Competing Interests}

The authors have declared that no competing interest exists.

\section{References}

1. Tanriover N, Kucukyuruk B, Ulu MO, Isler C, Sam B, Abuzayed B, et al. Microsurgical anatomy of the cisternal anterior choroidal artery with special emphasis on the preoptic and postoptic subdivisions. J Neurosurg. 2014; 120: 1217-28.

2. Morandi X, Brassier G, Darnault P, Mercier P, Scarabin JM, Duval JM. Microsurgical anatomy of the anterior choroidal artery. Surg Radiol Anat. 1996; 18: 275-80.

3. Marinkovic S, Gibo H, Brigante L, Nikodijevic I, Petrovic P. The surgical anatomy of the perforating branches of the anterior choroidal artery. Surg Neurol. 1999; 52: 30-6.

4. Herman LH, Fernando OU, Gurdjian ES. The anterior choroidal artery: an anatomical study of its area of distribution. Anat Rec. 1966; 154: 95-101.

5. Rhoton AL, Jr., Fujii K, Fradd B. Microsurgical anatomy of the anterior choroidal artery. Surg Neurol. 1979; 12: 171-87.

6. Neki H, Caroff J, Jittapiromsak P, Benachour N, Mihalea C, Ikka L, et al. Patency of the anterior choroidal artery covered with a flow-diverter stent. J Neurosurg. 2015; 123: 1540-5.

7. Takahashi S, Suga T, Kawata Y, Sakamoto K. Anterior choroidal artery: angiographic analysis of variations and anomalies. AJNR Am J Neuroradiol. 1990; 11: 719-29.

8. Antonietti LC, Glastonbury CM, Adler F, Wintermark M. Hyperplastic anterior choroidal artery identified using magnetic resonance angiography: a report of two cases. Cerebrovasc Dis. 2006; 22: 450-2.

9. Wollschlaeger G, Wollschlaeger PB, Meyer PG, Krautmann JJ. Widening or hyperplasia of the anterior choroidal artery. Criteria for the diagnosis. Radiology. 1969; 93: 1079-83.

10. Galatius-Jensen F, Ringberg V. Anastomosis between the Anterior Choroidal Artery and the Posterior Cerebral Artery Demonstrated by Arteriography. Radiology. 1963; 81: 942-4.

11. Abrahams JM, Hurst RW, Bagley LJ, Zager EL. Anterior choroidal artery supply to the posterior cerebral artery distribution: embryological basis and clinical implications. Neurosurgery. 1999; 44: 1308-14.

12. Takahashi S, Tobita M, Takahashi A, Sakamoto K. Retrograde filling of the anterior choroidal artery: vertebral angiographic sign of obstruction in the carotid system. Neuroradiology. 1992; 34: 504-7.

13. Choi $\mathrm{CY}$, Lee $\mathrm{CH}$. Transposition of anterior choroidal artery and posterior communicating artery origin. J Korean Neurosurg Soc. 2012; 52: 240-2.

14. Piotin M, Mounayer C, Spelle L, Williams MT, Moret J. Endovascular treatment of anterior choroidal artery aneurysms. AJNR Am J Neuroradiol. 2004; 25 : 314-8.

15. Andre A, Boch AL, Di Maria F, Nouet A, Sourour N, Clemenceau S, et al. Complication Risk Factors in Anterior Choroidal Artery Aneurysm Treatment. Clin Neuroradiol. 2017.

16. Yokota H, Noguchi H, Yokoyama K. Ruptured True Anterior Choroidal Artery Aneurysm in Cisternal Segment. World Neurosurg. 2016; 90: 701 e11e13.

17. Yang S, Yu JL, Wang HL, Wang B, Luo Q. Endovascular embolization of distal anterior choroidal artery aneurysms associated with moyamoya disease. A report of two cases and a literature review. Interv Neuroradiol. 2010; 16: 433-41.

18. McLaughlin N, Bojanowski MW. Ruptured aneurysm arising from the anterior choroidal artery's cisternal segment. Can J Neurol Sci. 2010; 37: 283-5.

19. Inagawa T, Matsuda Y, Kamiya K, Aoyama H, Nagasako R, Yamamoto M. Saccular aneurysm of the distal anterior choroidal artery--case report. Neurol Med Chir (Tokyo). 1990; 30: 498-502.

20. Dolati P, Sutherland G, Wong J, Hudon M, Goyal M. Distal anterior choroidal artery aneurysm following iatrogenic posterior cerebral artery occlusion : a case report and review of literature. Acta Neurochir (Wien). 2012; 154: 53-7.
21. Kurokawa $Y$, Ishizaki E, Inaba K. Incomplete oculomotor nerve palsy caused by an unruptured internal carotid-anterior choroidal artery aneurysm--case report. Neurol Med Chir (Tokyo). 2005; 45: 143-7.

22. Yoneoka Y, Ezuka I, Takai N, Oda T, Tamura T, Yamashita S. Ruptured distal anterior choroidal artery aneurysm presenting with casting intraventricular haemorrhage. Acta Neurochir (Wien). 1998; 140: 185-9.

23. Pavesi G, Amista P, Munari M, Gardiman MP. Intraventricular hemorrhage caused by peripheral anterior choroidal artery aneurysm rupture. A case report. Neuroradiol J. 2008; 21: 717-20.

24. Kang HS, Kwon BJ, Kwon OK, Jung C, Kim JE, Oh CW, et al. Endovascular coil embolization of anterior choroidal artery aneurysms. Clinical article. J Neurosurg. 2009; 111: 963-9.

25. Gimonet H, Desal HA, Mosimann PJ, Stracke P, Daumas-Duport B, Lintia-Gaultier A, et al. A new endovascular technique for small anterior choroidal artery aneurysms. A consecutive series using the 3-catheter-protective technique. J Neuroradiol. 2016; 43: 223-6.

26. Lehecka M, Dashti R, Laakso A, van Popta JS, Romani R, Navratil O, et al. Microneurosurgical management of anterior choroid artery aneurysms. World Neurosurg. 2010; 73: 486-99.

27. Kim BM, Kim DI, Shin YS, Chung EC, Kim DJ, Suh SH, et al. Clinical outcome and ischemic complication after treatment of anterior choroidal artery aneurysm: comparison between surgical clipping and endovascular coiling. AJNR Am J Neuroradiol. 2008; 29: 286-90.

28. Bohnstedt BN, Kemp WJ, 3rd, Li Y, Payner TD, Horner TG, Leipzig TJ, et al. Surgical treatment of 127 anterior choroidal artery aneurysms: a cohort study of resultant ischemic complications. Neurosurgery. 2013; 73: 933-9; discussion 9-40.

29. Nishihara J, Kumon Y, Matsuo Y, Sakaki S. A case of distal anterior choroidal artery aneurysm: case report and review of the literature. Neurosurgery. 1993; 32: 834-7; discussion 7.

30. Inci S, Arat A, Ozgen T. Distal anterior choroidal artery aneurysms. Surg Neurol. 2007; 67: 46-52; discussion

31. Schmalz PGR, Alturki A, Ogilvy CS, Thomas AJ. Ruptured Distal Anterior Choroidal Artery Aneurysm Treated with Superselective Provocative Testing and Coil Embolization. World Neurosurg. 2017.

32. Lee YS, Park J. Anterior choroidal artery aneurysm surgery: ischemic complications and clinical outcomes revisited. J Korean Neurosurg Soc. 2013; 54: 86-92.

33. Senturk C, Bandeira A, Bruneau M, Dewindt A, Baleriaux D, De Witte O, et al. Endovascular treatment of anterior choroidal artery aneurysms. J Neuroradiol. 2009; 36: 228-32.

34. van Son B, Vandevenne J, Viaene P. Bilateral anterior choroidal artery infarction presenting with progressive somnolence. J Stroke Cerebrovasc Dis. 2014; 23: e409-10.

35. Hupperts RM, Lodder J, Heuts-van Raak EP, Kessels F. Infarcts in the anterior choroidal artery territory. Anatomical distribution, clinical syndromes, presumed pathogenesis and early outcome. Brain. 1994; 117 (Pt 4): 825-34.

36. Derflinger S, Fiebach JB, Bottger S, Haberl RL, Audebert HJ. The progressive course of neurological symptoms in anterior choroidal artery infarcts. Int J Stroke. 2015; 10: 134-7.

37. Nelles M, Gieseke J, Flacke S, Lachenmayer L, Schild HH, Urbach H. Diffusion tensor pyramidal tractography in patients with anterior choroidal artery infarcts. AJNR Am J Neuroradiol. 2008; 29: 488-93.

38. Fisher M, Lingley JF, Blumenfeld A, Felice K. Anterior choroidal artery territory infarction and small-vessel disease. Stroke. 1989; 20: 1591-2.

39. Kim HC, Bae SY, Lee JW, Kim SE, Lee BI, Kim SE, et al. Vasculitis Findings for the Anterior Choroidal Artery in 3D-Time-of-Flight Magnetic Resonance Angiography. J Clin Neurol. 2017; 13: 308-9.

40. Leys D, Mounier-Vehier F, Lavenu I, Rondepierre P, Pruvo JP. Anterior choroidal artery territory infarcts. Study of presumed mechanisms. Stroke. 1994; 25: 837-42.

41. Levy R, Duyckaerts C, Hauw JJ. Massive infarcts involving the territory of the anterior choroidal artery and cardioembolism. Stroke. 1995; 26: 609-13.

42. Lee M, Saver JL, Hao Q, Starkman S, Salamon N, Ali LK, et al. Anterior choroidal artery ischaemic patterns predict outcome of carotid occlusion. J Neurol Neurosurg Psychiatry. 2012; 83: 586-90. 
43. Ois A, Cuadrado-Godia E, Solano A, Perich-Alsina X, Roquer J. Acute ischemic stroke in anterior choroidal artery territory. J Neurol Sci. 2009; 281: 80-4.

44. Alqahtani SA, Luby M, Nadareishvili Z, Benson RT, Hsia AW, Leigh R, et al. Perfusion Deficits and Association with Clinical Outcome in Patients with Anterior Choroidal Artery Stroke. J Stroke Cerebrovasc Dis. 2017; 26: 1755-9.

45. Touho H, Karasawa J, Ohnishi H, Nakase H, Furuoka N, Takaoka M, et al. Successful intra-arterial fibrinolysis of the anterior choroidal artery in the acute stage of internal carotid artery occlusion: case report. Surg Neurol. 1994; 41: 450-4.

46. Wu MC, Tsai LK, Wu CC, Yeh SJ, Tang SC, Chen YJ, et al. Thrombolytic therapy is an only determinant factor for stroke evolution in large anterior choroidal artery infarcts. J Stroke Cerebrovasc Dis. 2014; 23: 1089-93.

47. Chausson N, Joux J, Saint-Vil M, Edimonana M, Jeannin S, Aveillan M, et al. Infarction in the anterior choroidal artery territory: clinical progression and prognosis factors. J Stroke Cerebrovasc Dis. 2014; 23: 2012-7.

48. Suzuki J, Kodama N. Moyamoya disease--a review. Stroke. 1983; 14: 104-9.

49. Yu J, Shi L, Guo Y, Xu B, Xu K. Progress on Complications of Direct Bypass for Moyamoya Disease. Int J Med Sci. 2016; 13: 578-87.

50. Morioka M, Hamada J, Kawano T, Todaka T, Yano S, Kai Y, et al. Angiographic dilatation and branch extension of the anterior choroidal and posterior communicating arteries are predictors of hemorrhage in adult moyamoya patients. Stroke. 2003; 34: 90-5.

51. Liu W, Zhu S, Wang X, Yue X, Zhou Z, Wang H, et al. Evaluation of angiographic changes of the anterior choroidal and posterior communicating arteries for predicting cerebrovascular lesions in adult moyamoya disease. J Clin Neurosci. 2011; 18: 374-8.

52. Irikura K, Miyasaka Y, Kurata A, Tanaka R, Fujii K, Yada K, et al. A source of haemorrhage in adult patients with moyamoya disease: the significance of tributaries from the choroidal artery. Acta Neurochir (Wien). 1996; 138: 1282-6.

53. Huang CT, Hsu SK, Su IC. Regression of moyamoya-associated weak spots on the distal anterior choroidal artery following surgical revascularization. J Surg Case Rep. 2016; 2016.

54. Lee JK, Lee JH, Kim SH, Lee MC. Distal anterior choroidal artery aneurysm in a patient with moyamoya disease: case report. Neurosurgery. 2001; 48: 222-5.

55. Kameyama S, Honda Y, Tanimura K. Extravasation from anterior choroidal artery in a child with moyamoya disease--case report. Neurol Med Chir (Tokyo). 1991; 31: 162-4.

56. Takeyama E, Matsumori K, Sugimori T, Kagawa M. [A case of the anterior choroidal artery aneurysm combined with the abnormal intracranial vascular network (author's transl)]. No Shinkei Geka. 1976; 4: 1075-80.

57. Choulakian A, Drazin D, Alexander MJ. NBCA embolization of a ruptured intraventricular distal anterior choroidal artery aneurysm in a patient with moyamoya disease. J Neurointerv Surg. 2010; 2: 368-70.

58. Murakami $Y$, Sato $T$, Tamura $T$, Kyozuka $H$, Yasuda $S$, Nomura $Y$, et al. [A case of newly diagnosed moyamoya disease in a pregnant patient with a ruptured aneurysm of the distal anterior choroidal artery embolized using N-butyl cyanoacrylate]. No Shinkei Geka. 2014; 42: 961-6.

59. Oyama H, Noda S, Negoro M, Kinomoto T, Miyachi S, Kuwayama N, et al. Giant meningioma fed by the anterior choroidal artery: successful removal following embolization--case report. Neurol Med Chir (Tokyo). 1992; 32: $839-41$.

60. Gupta N. Choroid plexus tumors in children. Neurosurg Clin N Am. 2003; 14: 621-31.

61. Ben Nsir A, Gdoura Y, Thai QA, Zhani Kassar A, Hattab N, Jemel H. Intraventricular Glioblastomas. World Neurosurg. 2016; 88: 126-31.

62. Schroeder HW. Intraventricular tumors. World Neurosurg. 2013; 79: S17 e5-9.

63. James RF, Kramer DR, Page PS, Gaughen JR, Jr., Martin LB, Mack WJ. Strategic and Technical Considerations for the Endovascular Embolization of Intracranial Meningiomas. Neurosurg Clin N Am. 2016; 27: 155-66.

64. Nakase H, Ohnishi H, Touho H, Itoh T, Karasawa J. Vasculopathy of the anterior choroidal artery following intra-arterial chemotherapy--case report. Neurol Med Chir (Tokyo). 1994; 34: 620-3.

65. Vulliemoz S, Pegna AJ, Annoni JM, Yilmaz H, Willi JP, Spinelli L, et al. The selective amobarbital test in the anterior choroidal artery: perfusion pattern assessed by intraarterial SPECT and prediction of postoperative verbal memory. Epilepsy Behav. 2008; 12: 445-55.

66. Trivelato FP, Manzato LB, Rezende MT, Barroso PM, Faleiro RM, Ulhoa AC. Preoperative embolization of choroid plexus papilloma with Onyx via the anterior choroidal artery: technical note. Childs Nerv Syst. 2012; 28: 1955-8.

67. Fujita K, Matsumoto S. Anterior choroidal artery arteriovenous malformation. Its clinical manifestations and surgical treatment. Surg Neurol. 1984; 22: $347-52$

68. Jiao $\mathrm{Y}$, Lin F, Wu J, Li H, Chen $\mathrm{X}, \mathrm{Li} \mathrm{Z}$, et al. Brain Arteriovenous Malformations Supplied by the Anterior Choroidal Artery: Treatment Outcomes and Risk Factors for Worsened Muscle Strength After Surgical Resection. World Neurosurg. 2017; 104: 567-74

69. Lawton MT, Rutledge WC, Kim H, Stapf C, Whitehead KJ, Li DY, et al. Brain arteriovenous malformations. Nat Rev Dis Primers. 2015; 1: 15008.

70. Lv X, Hu X, Li W, He H, Jiang C, Li Y. Curative and adjunctive AVM Onyx embolization of AVMs through the choroidal arteries. Interv Neuroradiol. 2017; 23 : 392-8.

71. Hodes JE, Aymard A, Casasco A, Rufenacht D, Reizine D, Merland JJ. Embolization of arteriovenous malformations of the temporal lobe via the anterior choroidal artery. AJNR Am J Neuroradiol. 1991; 12: 775-80.
72. Elkordy A, Endo $\mathrm{H}$, Sato $\mathrm{K}$, Matsumoto $\mathrm{Y}$, Kondo $\mathrm{R}$, Niizuma $\mathrm{K}$, et al. Embolization of the choroidal artery in the treatment of cerebral arteriovenous malformations. J Neurosurg. 2017; 126: 1114-22.

73. Fernandez-Miranda JC, de Oliveira E, Rubino PA, Wen HT, Rhoton AL, Jr. Microvascular anatomy of the medial temporal region: part 1: its application to arteriovenous malformation surgery. Neurosurgery. 2010; 67: ons237-76; discussion ons76.

74. Fujii K, Lenkey C, Rhoton AL, Jr. Microsurgical anatomy of the choroidal arteries: lateral and third ventricles. J Neurosurg. 1980; 52: 165-88.

75. Isozaki $\mathrm{M}$, Satow $\mathrm{T}$, Matsushige $\mathrm{T}$, Mori $\mathrm{H}$, lihara $\mathrm{K}$. Superselective Provocative Test with Propofol Using Motor-Evoked Potential Monitoring for Managing Cerebral Arteriovenous Malformations Fed by the Anterior Choroidal Artery. J Stroke Cerebrovasc Dis. 2016; 25: e153-7.

76. Dowd CF, Halbach VV, Barnwell SL, Higashida RT, Hieshima GB. Particulate embolization of the anterior choroidal artery in the treatment of cerebral arteriovenous malformations. AJNR Am J Neuroradiol. 1991; 12: 1055-61.

77. Bologna M, Suppa A, Di Stasio F, Conte A, Fabbrini G, Berardelli A. Neurophysiological studies on atypical parkinsonian syndromes. Parkinsonism Relat Disord. 2017.

78. Przedborski S. The two-century journey of Parkinson disease research. Nat Rev Neurosci. 2017; 18: 251-9.

79. Kim JS. Involuntary movements after anterior cerebral artery territory infarction. Stroke. 2001; 32: 258-61.

80. Demirkiran M, Bozdemir H, Sarica Y. Vascular parkinsonism: a distinct, heterogeneous clinical entity. Acta Neurol Scand. 2001; 104: 63-7.

81. Cooper IS. Ligation of the anterior choroidal artery for involuntary movements; parkinsonism. Psychiatr Q. 1953; 27: 317-9.

82. Cooper IS. Anterior chorodial artery ligation for involuntary movements. Science. 1953; 118: 193.

83. Rand RW, Stern WE, Orr JK. Parkinsonism; early results of occlusion of the anterior choroidal artery. Calif Med. 1954; 81: 276-8.

84. Morgenstern LB, Hankins LL, Grotta JC. Anterior choroidal artery aneurysm and stroke. Neurology. 1996; 47: 1090-2.

85. Ogrenci A, Eksi MS, Gun B, Koban O. Traumatic basal ganglia hematoma following closed head injuries in children. Childs Nerv Syst. 2016; 32: 1237-43.

86. Cressman MR, Hayes GJ. Traumatic aneurysm of the anterior choroidal artery. Case report. J Neurosurg. 1966; 24: 102-4.

87. Kinoshita Y, Yasukouchi H, Harada A, Tsuru E, Okudera T. [Case report of traumatic hemorrhage from the anterior choroidal artery]. No Shinkei Geka. 2008; 36: 891-4.

88. Mosberg WH, Lindenberg R. Traumatic hemorrhage from the anterior choroidal artery. J Neurosurg. 1959; 16: 209-21.

89. Sim KB, Park SQ, Choi HA, Kim DH. Demonstration of traumatic subarachnoid hemorrhage from the anterior choroidal artery. J Korean Neurosurg Soc. 2014; 56: 531-3.

90. Filter ER, Fernandes JR. Fatal traumatic subarachnoid hemorrhage due to assault-related tear of the basilar artery. J Forensic Leg Med. 2009; 16: 414-6.

91. Pollanen MS, Deck JH, Blenkinsop B. Injury of the tunica media in fatal rupture of the vertebral artery. Am J Forensic Med Pathol. 1996; 17: 197-201.

92. Jenkins JM, Norton J, Hampton T, Weeks R. Rare case of bilateral traumatic internal carotid artery dissection. BMJ Case Rep. 2016; 2016

93. Yu J, Shi L, Lv X, Wu Z, Yang H. Intracranial non-galenic pial arteriovenous fistula: A review of the literature. Interv Neuroradiol. 2016; 22: 557-68.

94. Rivera R, Blanc R, Piotin M, Spelle L, Moret J. Single hole cerebral arteriovenous fistula between the anterior choroidal artery and the basal vein of Rosenthal in a child. Childs Nerv Syst. 2009; 25: 1521-3.

95. Wang YC, Wong HF, Yeh YS. Intracranial pial arteriovenous fistulas with single-vein drainage. Report of three cases and review of the literature. J Neurosurg. 2004; 100: 201-5.

96. Yu J, Shi L, Yuan Y, Wu W. Research progress on complications of intracranial aneurysms with flow-diverting stents. Int J Clin Exp Med. 2016; 9: 13340-50.

97. Rangel-Castilla L, Munich SA, Jaleel N, Cress MC, Krishna C, Sonig A, et al. Patency of anterior circulation branch vessels after Pipeline embolization: longer-term results from 82 aneurysm cases. J Neurosurg. 2017; 126: 1064-9.

98. Bhogal P, Ganslandt O, Bazner H, Henkes H, Perez MA. The Fate of Side Branches Covered by Flow Diverters-Results from 140 Patients. World Neurosurg. 2017; 103: 789-98

99. Vedantam A, Rao VY, Shaltoni HM, Mawad ME. Incidence and clinical implications of carotid branch occlusion following treatment of internal carotid artery aneurysms with the pipeline embolization device. Neurosurgery. 2015; 76: 173-8; discussion 8.

100. Brinjikji W, Kallmes DF, Cloft HJ, Lanzino G. Patency of the anterior choroidal artery after flow-diversion treatment of internal carotid artery aneurysms. AJNR Am J Neuroradiol. 2015; 36: 537-41.

101. Fiorella D, Lylyk P, Szikora I, Kelly ME, Albuquerque FC, McDougall CG, et al. Curative cerebrovascular reconstruction with the Pipeline embolization device: the emergence of definitive endovascular therapy for intracranial aneurysms. J Neurointerv Surg. 2009; 1: 56-65. 